\title{
NATURAL ORGANIC MATTER FRACTIONATION ALONG THE TREATMENT OF WATER FOR HUMAN CONSUMPTION
}

R.F. VIEIRA ${ }^{1}$

A.T. BERENGUEL ${ }^{2}$

M.A. SILVA ${ }^{2}$

J.S. VILAÇA ${ }^{2}$

V.F. DOMINGUES ${ }^{1}$

S.A. FIGUEIREDO ${ }^{1,}$

Received: $30 / 03 / 12$

Accepted: 17/05/12
${ }^{1}$ REQUIMTE, Instituto Superior de Engenharia do Porto Instituto Politechnico do Porto

Rua Dr. António Bernardino de Almeida, 431 4200-072 Porto, Portugal

${ }^{2}$ Águas do Douro e Paiva, S.A.

Rua de Vilar, 235, 5०, 4050 - 626 Porto, Portugal

*to whom all correspondence should be addressed: e-mail: saf@isep.ipp.pt

\section{ABSTRACT}

The main objective of this study was to characterize the organic matter present in raw water and along the treatment process, as well as its seasonal variation. A natural organic matter fractionation approach has been applied to Lever water treatment plant located in Douro River, in Oporto (Portugal).

The process used was based on the sorption of dissolved organic matter in different types of ion exchange resins, DAX-8, DAX-4 and IRA-958, allowing its separation into four fractions: very hydrophobic acids (VHA), slightly hydrophobic acids (SHA), charged hydrophilic (CHA) and hydrophilic neutral (NEU). The dissolved organic carbon (DOC) determination was used to quantify dissolved organic matter. Samples were collected monthly, during approximately one year, from raw water captured at the surface and under the bed of the river, and after each step of the treatment: pre-filtration in sand/anthracite filters, ozonation, coagulation/flocculation, counter current dissolved air flotation and filtration (CoCoDAFF) and chlorination.

The NEU fraction showed a seasonal variation, with maximum values in autumn for the sampling points corresponding to raw water captured at the surface and under the bed of the river. It was usually the predominating fraction and did not show a significant decrease throughout the treatment. Nevertheless their low concentration, the same occurred for the CHA and VHA fractions. There was an overall decrease in the SHA fraction throughout the water treatment (especially after CoCoDAFF and ozonation) as well as in the DOC.

The TSUVA 254 values obtained for raw water generally varied between 2.0 and $4.0 \mathrm{~L} \mathrm{mgC}^{-1} \mathrm{~m}^{-1}$ and between 0.75 and $1.78 \mathrm{~L} \mathrm{mgC}^{-1} \mathrm{~m}^{-1}$ for treated water. It was observed a decrease of TSUVA values along the treatment, especially after ozonation.

These results may contribute to a further optimization in the process of treating water for human consumption.

KEYWORDS: dissolved organic carbon (DOC), chemical fractionation, ion exchange resins, natural organic matter (NOM), specific ultraviolet absorbance (SUVA), water treatment.

\section{INTRODUCTION}

Natural organic matter (NOM) in water is a major concern and should be removed from drinking water because of the following reasons: it affects organoleptic properties of water (colour, taste and odour); it reacts with most disinfectants used in water treatment; it influences disinfectant demand, disinfection process design, operation and maintenance; it can produce disinfection by-products of various kinds; it affects biostability and biological regrowth in distribution systems (Juhna and Melin, 2006). 
Water chlorination has been reported to result in the formation of a large number of compounds, known as chlorination by-products including trihalomethanes (THMs), haloacetic acids (HAAs), chloral hydrate, haloacetonitriles, haloketones and chloropicrin (Nikolaou et al., 1999). THMs and HAAs are described as the most abundant chlorination by-products detected (Nikolaou et al., 2003). They are considered potentially carcinogenic, and in most industrialized countries, standards for THMs have been established within drinking water regulations. Most recently, efforts have been made to a better documentation of the occurrence of HAAs (Rodriguez et al., 2007).

In recent years, attention has been focused on the carbonaceous organic matter that can be used by microorganims as source of nutrients. This fraction, called biodegradable organic matter, is favourably used by bacteria as substrate promoting their growth. The growth of bacteria in distribution networks is not desirable because some of these bacteria can be potentially pathogenic for humans (e.g. Legionella pneumophila and Mycobacterium avium). Bacterial growth in the network is mainly occurring in biofilm on surface of pipes. The biofilm can be the environment where invertebrates can develop and pathogens are protected from disinfectant effect. To reduce these problems, the biodegradable organic matter levels in drinking water leaving the treatment plant should be as low as possible (Juhna and Melin, 2006).

Dissolved organic matter (DOM) derives from different sources, such as vegetation, soil, wastewater and agricultural return, and may have distinctive chemical characteristics associated with its origins. The contribution of each carbon source is potentially seasonally dependent. The reactivity of DOM in the formation of THMs could be source dependent because the aromatic carbon content varies with different sources. Not all aromatic carbons are equally reactive with disinfectants, depending on the positions of functional groups, namely hydroxyl and carboxylate (Chow et al., 2005).

DOM is operationally defined as that portion passing through a $0.45 \mu \mathrm{m}$ pore-size filter. The size fraction greater than $0.45 \mu \mathrm{m}$, such as particulate organic matter, can be removed effectively with conventional treatment methods such as coagulation and filtration processes. DOM is the fraction of natural organic matter that is of greatest interest to water industry therefore it is under research. Various physical and chemical fractionation techniques have been applied to identify the major reactive disinfection by-products components in DOM. The most used fractionation techniques are XAD fractionation, ultrafiltration and size exclusion chromatography (Chow et al., 2005).

Chow et al. (2004) consider that the fractionation technique using ion exchange resins could be applied in the operation of the treatment plant and could potentially guide treatment operators to control and monitor the treatment processes in the most effective way for NOM removal. It can be carried out on the original sample without the need of a pre-concentration step, thereby maintaining fractionation consistency and comparability between samples (Chow et al., 2005). For this reason it was selected for this work. The selected method was proposed by Chow et al. (2004) and had its original version by Leenheer and Huffman (1976). It allows the separation of dissolved organic carbon into four NOM fractions, very hydrophobic acids (VHA), slightly hydrophobic acids (SHA), hydrophilic charged (CHA) and hydrophilic neutral (NEU). An alternative conditioning method with phosphoric acid and sodium hydroxide (instead of methanol and acetonitrile) used by Smith and Alqabany (2009) was also tested.

Although XAD fractionation has been widely used in the last decades, Gadmar et al. (2005) detected that the division into hydrophobic and hydrophilic fractions are not independent of the NOM concentration and not constant during the procedure, furthermore the XAD-8 fractions may undergo irreversible alteration of structure due to the procedure of storage that will influence the interpretation of results.

The specific UV absorbance (SUVA ${ }_{254}$ ) defined as the UV absorbance at $254 \mathrm{~nm}$ normalized for dissolved organic carbon (DOC) concentration was evaluated in all samples. This parameter can provide reliable information about the characteristics of DOM and its tendency to form disinfection by-products during water treatment (Chow et al., 2005). While it is a good predictor of general chemical characteristics (aromaticity) of DOC, it does not provide information about reactivity of DOC derived from different types of source materials (Weishaar et al., 2003).

The main objective of this study was to characterize the organic matter present in raw water from Douro River (Oporto district, Portugal) and along the treatment process in Lever plant, as well as the seasonal variation of its fractions, in order to contribute to an optimization in the process of treating water for human consumption. 


\section{MATERIALS AND METHODS}

The fractionation procedure was based on sorption onto three different resins according to the method published by Chow et al. (2004): Supelite DAX-8 (Supelco), Amberlite XAD-4 (Supelco) and Amberlite IRA-958 chloride form (Fluka) - the DAX resins were formerly known as XAD resins. This technique allows the separation in four fractions: VHA (sorbed by DAX-8), SHA (sorbed by XAD-4), CHA (sorbed by IRA-958) and NEU, which was not sorbed on any of the ion exchange resins.

Conditioning of resins DAX-8 and XAD-4 was performed using methanol (p.a., Sigma-Aldrich) and deionised water; acetonitrile (>99,9\%, Lichrosolv) was also used for IRA-958 conditioning. In order to avoid contamination by organic solvents, another conditioning method using sodium hydroxide (Pronolab) and phosphoric acid (85\%, Panreac) was also used, which has been tested by Smith and Alqabany (2009).

In the organic conditioning, methanol was added to the resin (before any utilization), sufficient to cover the mass with a height of $2.5 \mathrm{~cm}$. The resin was stirred ( $1 \mathrm{~min}$ ) to ensure complete mixing and allowed to settle $(15 \mathrm{~min})$, then it was carefully decanted (almost completely) and replaced by deionised water. The aqueous mixture was stirred and allowed to settle (5-10 min). Further rinsing of the resin was performed, in each contact $500 \mathrm{~mL}$ of deionized water were used and discarded (1500 $\mathrm{mL}$ total volume). The last contact was left overnight and then washed with $500 \mathrm{~mL}$ successive portions (1500 mL total volume), making a total of $3000 \mathrm{~mL}$ of deionized water used to wash each resin. The conditioning of IRA-958 was performed by using the same procedure as for the resin DAX-8 and XAD-4, with the exception that the conditioning with methanol was followed by a subsequent conditioning with the same volume of acetonitrile and then successive rinsing with deionised water. Samples were taken from the last rinsing of each resin for analysis of DOC, to test organic contamination.

An alternative conditioning method without organic solvents (Smith and Alqabany, 2009) was used: the resins were prepared for operation by washing it with $200 \mathrm{~mL}$ of deionized water, followed by immersion in $200 \mathrm{~mL}$ of $\mathrm{NaOH}(0.1 \mathrm{~N})$ overnight, and then washed with $500 \mathrm{~mL}$ of deionized water; then the resin was washed again with $200 \mathrm{~mL}$ of $\mathrm{NaOH}(0.1 \mathrm{~N}), 100 \mathrm{~mL}$ of deionized water and then $100 \mathrm{~mL}$ of $\mathrm{H}_{3} \mathrm{PO}_{4}(0.1 \mathrm{~N})$ and finally washed with $200 \mathrm{~mL}$ of deionized water.

Three borosilicate glass columns (15 cm length; $2.5 \mathrm{~cm}$ internal diameter) for DAX-8, XAD-4 and IRA-958 resins were set up in series (Figure 1). The $500 \mathrm{~mL}$ sample was filtered through a $0.45 \mu \mathrm{m}$ nylon membrane filter and acidified to $\mathrm{pH} 2$ with $\mathrm{HCl}(37 \%$, Carlo Erba Reagents) and was passed through the DAX-8 column at $3.0 \mathrm{~mL} \mathrm{~min}^{-1}$. The first $30 \mathrm{~mL}$ were discarded and the remaining effluent $(470 \mathrm{~mL})$ was collected. A sample of $50 \mathrm{~mL}$ was collected in duplicate for DOC analysis. The remaining effluent $(370 \mathrm{~mL})$ was passed through the XAD-4 column and the first $30 \mathrm{~mL}$ were discarded. After sampling $50 \mathrm{~mL}$ (in duplicate) for DOC analysis, the effluent from XAD-4 column was adjusted to $\mathrm{pH} 8$ with $\mathrm{NaOH}$ (Pronolab) and was pumped through the IRA-958 column, with the first $30 \mathrm{~mL}$ again being discarded. Duplicate samples $(50 \mathrm{~mL})$ were collected at the column outlet for $\mathrm{DOC}$ analysis. The installation set-up is shown in Figure 1. All pH adjustments were performed using concentrated solutions to minimise dilution of the sample. Samples were collected in glass vials (adapted to the automatic sampler) and preservation was performed by acidification with concentrated $\mathrm{HCl}$ (until $\mathrm{pH}<2$ ) and refrigeration. The DOC determination was performed by a TOC analyser (Shimadzu TOC-V CPH) with automatic sampler (Shimadzu ASI-V) for each original sample and for samples resulting from the fractionation process. SUVA 254 was determined by using a UV-VIS spectrophotometer (Shimadzu UV260).

Samples of raw water from Douro River were collected monthly, from July 2010 to June 2011, both from raw water captured at the surface and under the bed of the river. Samples were also collected in the Lever treatment plant after each step of the treatment process, as shown in Figure 2.

\section{CALCULATIONS PERFORMED}

The dermination of the concentration of each fraction of DOM was based in the DOC values in accordance with following equations:

$$
\begin{aligned}
& \text { VHA }=\text { DOC } \text { original sample }- \text { DOC } \\
& \text { DAX-8 effluent } \\
& \text { SHA }=\text { DOC } \text { DAX-8 effluent }- \text { DOC } \text { XAD-4 effluent } \\
& \text { CHA }=\text { DOC XAD-4 effluent }- \text { DOC IRA-958 effluent } \\
& \text { NEU }=\text { DOC IRA-958 effluent }
\end{aligned}
$$




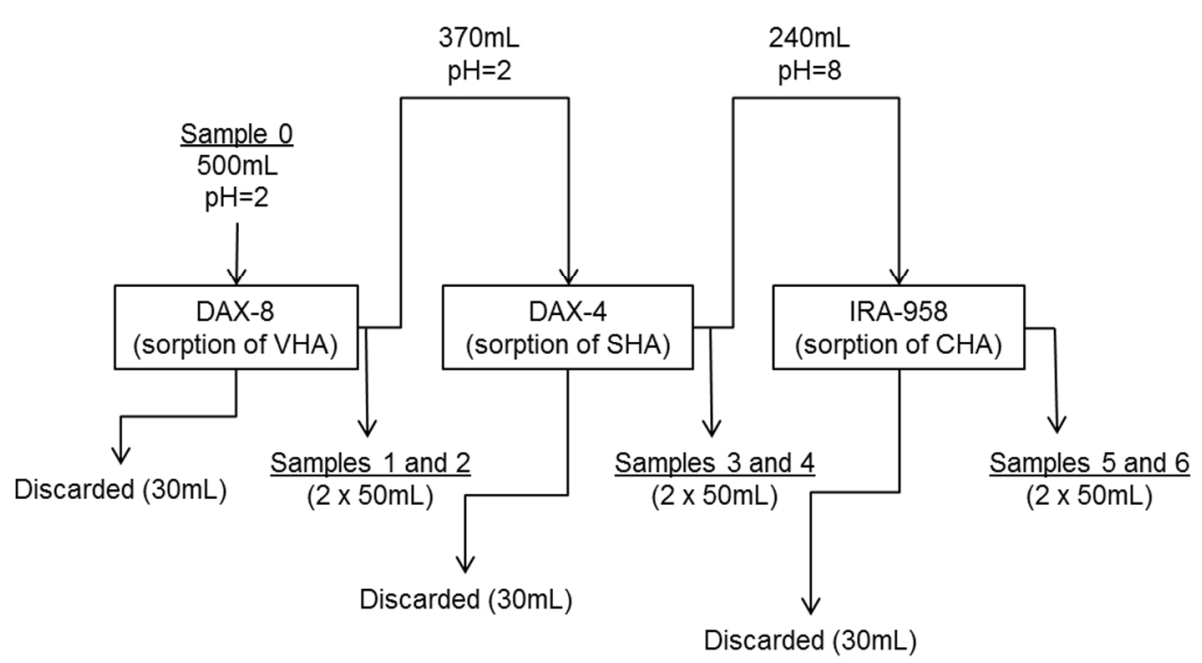

Figure 1. Illustration of the experimental set up

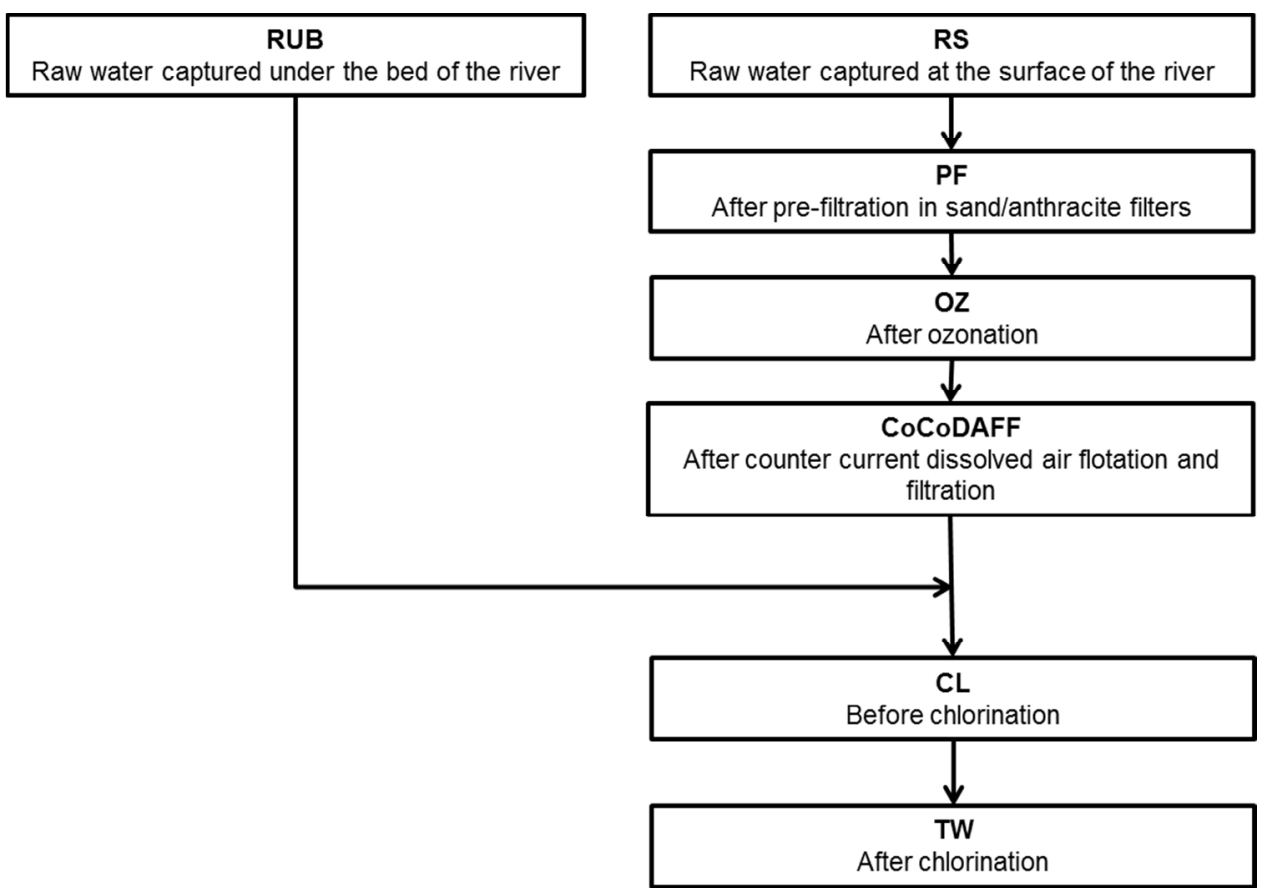

Figure 2. Scheme of sampling along the treatment process

\section{RESULTS}

Lever treatment plant is located in Douro River (Oporto district, Portugal) and treats around 300,000 $\mathrm{m}^{3} \mathrm{~d}^{-1}$. Samples of raw water both collected at the surface (RS) and under the bed of the river (RUB) were characterized for DOC content and DOM fractionation. The same characterization was performed for samples obtained after each step of the treatment process (Figure 2), pre-filtration in sand/anthracite filters (PF), ozonation (OZ), coagulation/flocculation with aluminium sulphate (CF), counter current dissolved air flotation and filtration (CoCoDAFF), before chlorination (CL) and after treatment (TW).

\subsection{NOM fractionation}

The fractionation of DOM was performed for all samples. The values obtained for VHA, SHA, CHA and NEU fractions are presented in Figure 3 for raw (RS and RUB) and treated water (TW) along the sampling period (from July 2010 to June 2011). Although extreme care was taken to avoid contamination some situations of organic contamination were detected, some of them might be due to the conditioning with organic solvents. Therefore these values were not considered in this study and the alternative conditioning method with inorganic solutions was adopted since January 2011. 
Although the inorganic conditioning method reduced the level of contamination it was not completely prevented due to the low concentration of organic mater evaluated in this work. The work with low organic mater concentrations has already been considered a limitation of this fractioning method by Chow et al. (2005).

NEU fraction includes short-chain aliphatic amines, alcohols, aldehydes, esters, ketones, short-chain aliphatic amides, polyfunctional alcohols, carbohydrates, cyclic amides and mostly polysaccharides (Swietlik et al., 2004). It was usually the predominating one. A seasonal variation of NEU was verified, with maximum values in autumn, for raw water captured superficially (RS) and under the bed of the river (RUB). These results are consistent with the observations of Smith and Alqabany (2009) in Nilo River (Egypt), nevertheless the average NEU concentration is higher $3.80 \mathrm{mgC} \mathrm{L}^{-1}$. The hydrophobic fraction was not the largest one, in contrast to many reports in the literature (Chow et al., 2005). Indeed Chow et al. (2004) presents the SHA fraction as dominant in Myponga reservoir (Australia). Again a higher organic matter concentration was observed, 5.1, 1.8, 1.6 and $0.8 \mathrm{mgC} \mathrm{L}^{-1}$ respectively for the VHA, SHA, CHA and NEU when compared with average concentration of 0.19 , $0.55,0.14$ and $1.18 \mathrm{mgC} \mathrm{L}^{-1}$ respectively, for raw surface water from Douro River.

In order to evaluate the evolution of each fraction of DOM its average values are represented along the treatment process in Figure 4. Raw water (RS and RUB) was mostly composed by NEU and it did not show a significant reduction throughout the treatment. The same occurred for the $\mathrm{CHA}$ fraction in spite of its low concentration. The other fractions, SHA and VHA presented also low concentrations and have suffered a decrease throughout the water treatment (mostly after CoCoDAFF), especially the SHA fraction. There was also an overall decrease in the content of DOC throughout treatment.

The CoCoDAFF step was more efficient step towards the removal of the hydrophobic fractions, SHA and VHA. These results are in accordance with the observations of Buchanan et al. (2005) who consider the NEU fraction the most difficult to remove, as most of the components in this fraction were refractory to both biological (sand-attached bacteria) and photo-oxidative (UV and vacuum UV radiation) processes. Therefore, enhanced removal of the dominant NEU fraction would be required to increase the effectiveness and potential of the treatment.
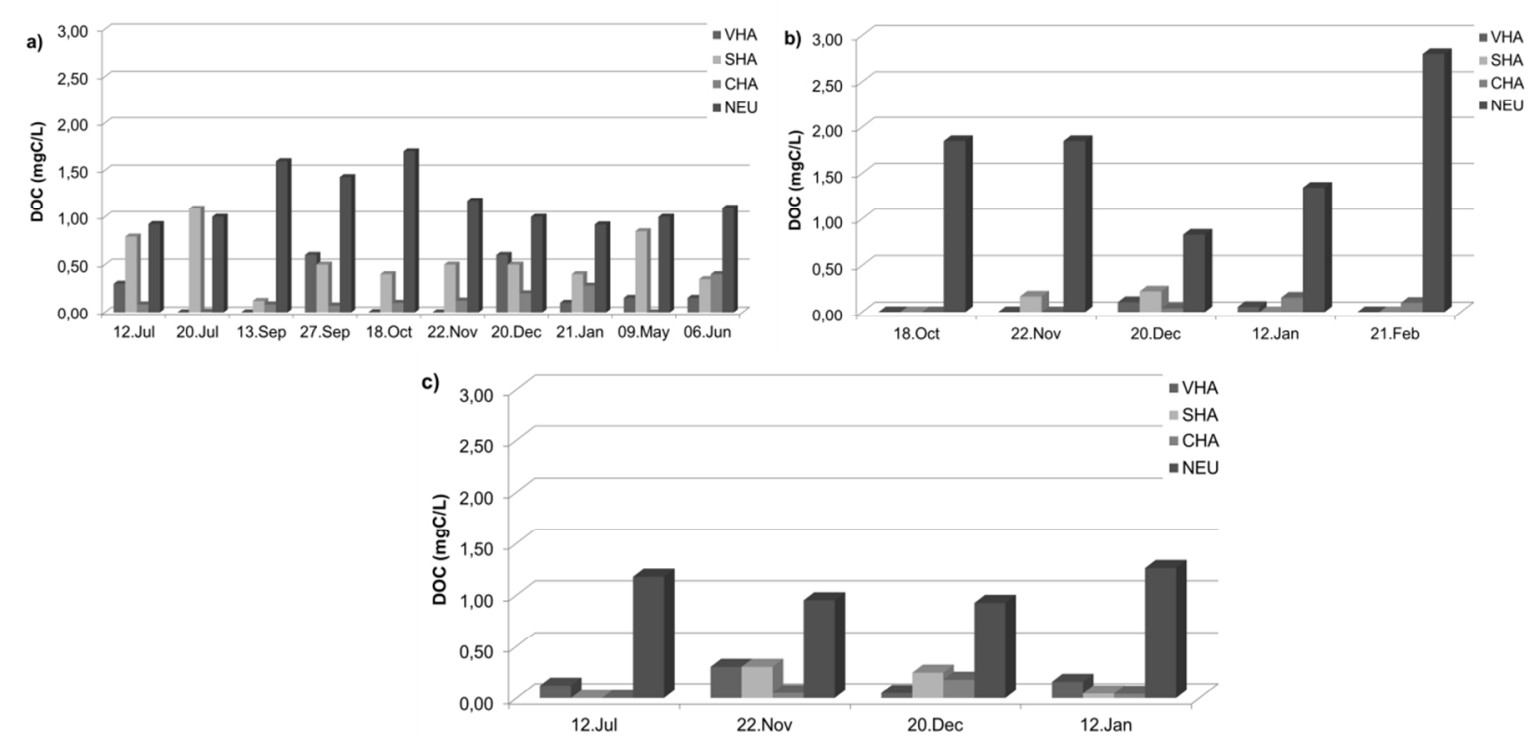

Figure 3. Concentration of VHA, SHA, CHA and NEU fractions for (a) RS, (b) RUB and (c) TW along the sampling period 


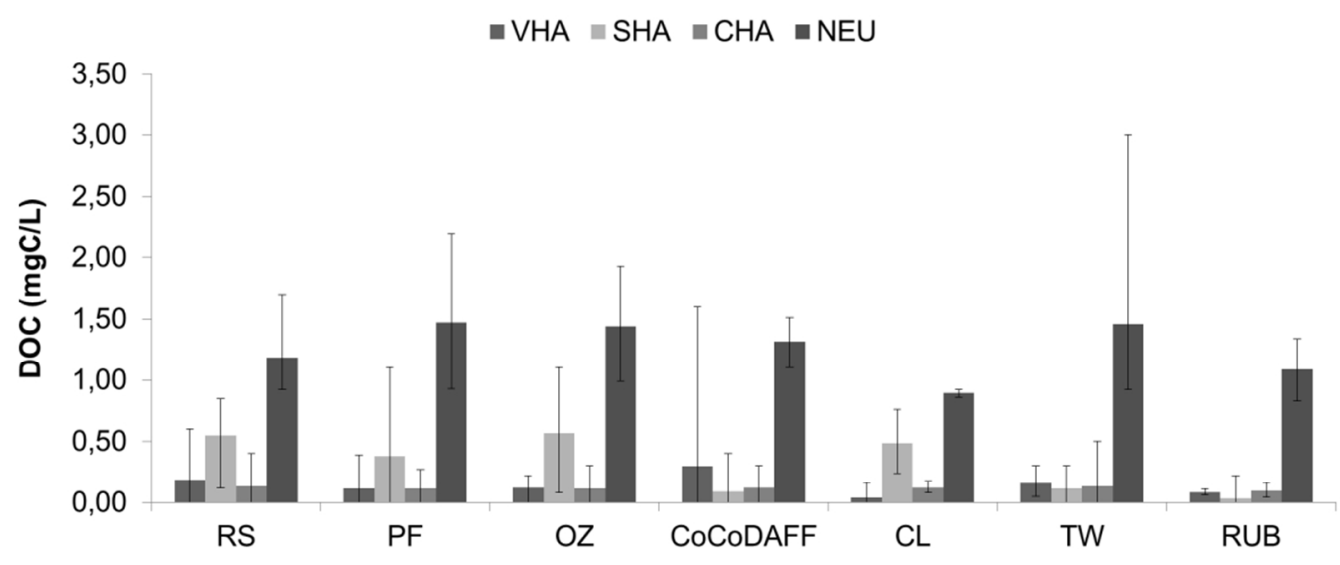

Figure 4. Average concentration of VHA, SHA, CHA and NEU fractions along the treatment and respective maximum and minimum values

\subsection{TSUVA and SUVA evaluation}

The concentration of TSUVA 254 , UV absorbance at $254 \mathrm{~nm}$ normalized for total organic carbon, was determined for all original samples. It is considered an useful indicator of the presence of humic compounds (aromatic). However its utility as indicator of the natural organic matter reactivity upon disinfectants is complex because some compounds may not absorb at $254 \mathrm{~nm}$ but may react with disinfectants (Weishaar et al., 2003). This parameter can also be used as an indicator of the water treatability by coagulation since compounds with high hydrofobicity (aromatic) are efficiently removed by coagulation. Their evolution throughout time (from July 2010 to June 2011) for raw (RS and RUB) and treated water (TW) is represented in Figure 5.

The DOC in raw surface water showed no significant variation (around $2 \mathrm{mgC} \mathrm{L}^{-1}$ ) during the sampling period, except in January when sampling occurred after a long rainfall period, which caused leaching of organic matter. It caused also an increase of TSUVA concentration in raw surface water. Nevertheless this exception, in Figure 5 there is no evidence of seasonal variance both in raw (RS and RUB) and treated water (TW). The highest values were obtained for raw water samples.

The TSUVA values obtained were generally below $3 \mathrm{~L} \mathrm{mgC}^{-1} \mathrm{~m}^{-1}$ for RUB water, which correspond to the presence of non-humic substances that are considered biodegradable (Edzwald and Benschoten, 1990). Raw surface water usually had $2.0-4.0 \mathrm{~L} \mathrm{mgC}^{-1} \mathrm{~m}^{-1}$, which are common values for raw water (Chow et al., 2005). Therefore it may contain humic and non-humic compounds, since between 4 and $5 \mathrm{~L} \mathrm{mgC}^{-1} \mathrm{~m}^{-1}$ predominate humic materials (Edzwald and Benschoten, 1990).

The treatment caused a reduction of the TSUVA values, corresponding to $0.75-2.0 \mathrm{~L} \mathrm{mgC}^{-1} \mathrm{~m}^{-1}$ for treated water, which are considered low values.

The average concentration of TSUVA and SUVA (after filtration), and the corresponding SUVA value in the NEU fraction (after IRA-958) were determined for each sample and their evolution along the treatment is compared in Figure 6. The TSUVA values (initial sample) are always higher than SUVA because the filter removes particulate organic matter. The SUVA values obtained after passing the IRA-958 resin are even lower, as it was expected because the NEU fraction is not aromatic.

Along the treatment of raw surface water it is observed a decrease in the values of TSUVA, SUVA and SUVA in the NEU fraction, having a sharp decrease after ozonation. The apparent increase observed before chlorination $(\mathrm{CL})$ is due to the mixture of raw water captured under the bed of the river, which did not suffer any treatment until this step of the treatment process. The average value of TSUVA was $1.31 \mathrm{~L} \mathrm{mgC}^{-1} \mathrm{~m}^{-1}$ for treated water. This value is lower than $2 \mathrm{~L} \mathrm{mgC}^{-1} \mathrm{~m}^{-1}$, which is the lower limit for the use of coagulation (Weishaar et al., 2003) and it indicates that the water contains biodegradable fractions which are removable with biofiltration (Juhna and Melin, 2006). The biofilter would remove biodegradable organic matter and therefore would increase the biostability of the water and reduce the risk of disinfection by-products formation in the chlorination process. The process could be combined with ozonation since it increases the amount of biodegradable matter in 
the water (Juhna and Melin, 2006). This is already a step of the process of Lever water treatment plant.

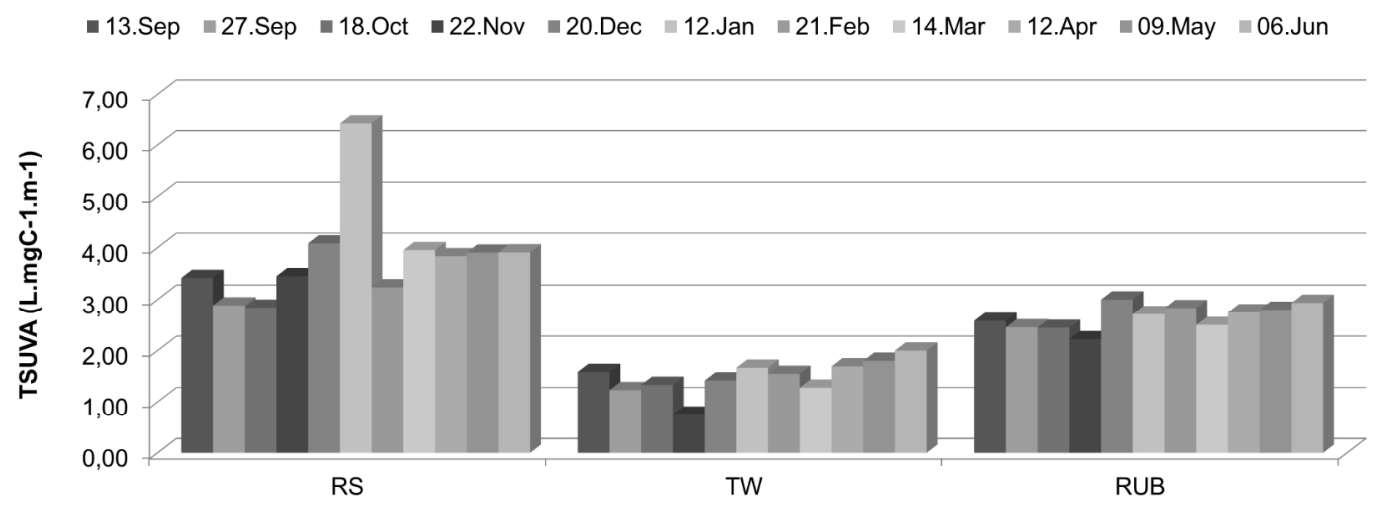

Figure 5. Concentration of TSUVA 254 for RS, RUB and TW along the sampling period

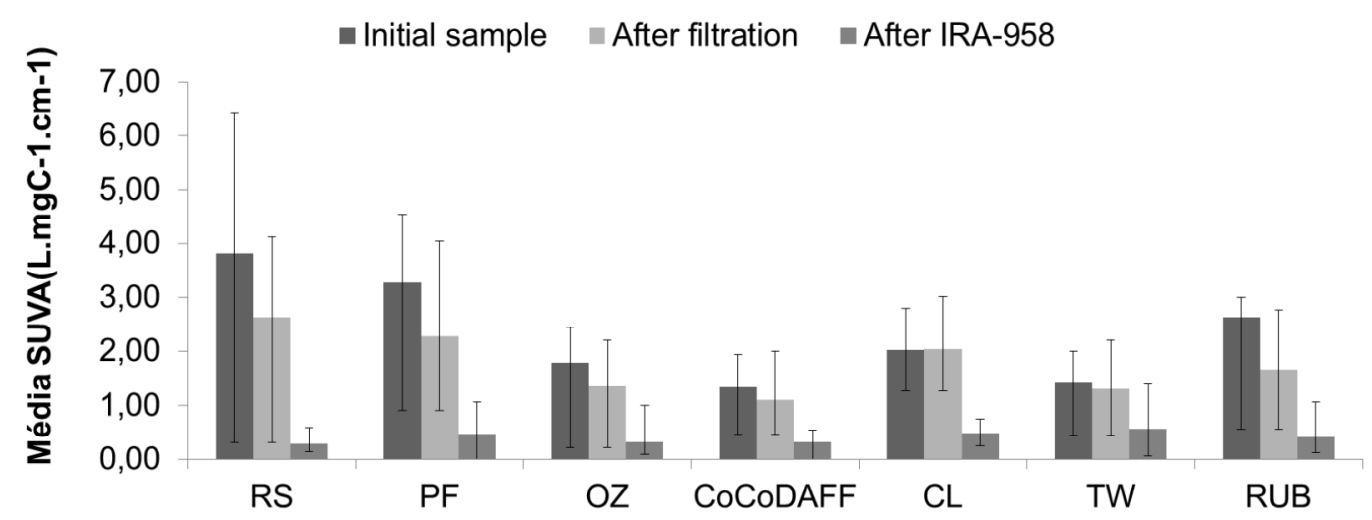

Figure 6. Average concentration of TSUVA 254, SUVA $_{254}$ and SUVA 254 in the NEU fraction, and respective maximum and minimum values, along the treatment

\section{CONCLUSIONS}

The fractionation of water samples revealed that the NEU fraction was always the dominant fraction. This fraction did not show a significant reduction throughout the treatment. There was an overall decrease of the hydrofobic fractions, especially SHA, during treatment (mostly CoCoDAFF) and an overall decrease in the content of DOC.

Raw water usually had a TSUVA concentration of $2.0-4.0 \mathrm{~L} \mathrm{mgC}^{-1} \mathrm{~m}^{-1}$, therefore it may contain humic and non-humic compounds. Owing the fact that non-humic substances, which are considered biodegradable, are predominant therefore biofiltration might be suggested to enhance DOC removal.

The treatment caused a reduction of the TSUVA values, corresponding to $0.75-2.0 \mathrm{~L} \mathrm{mgC}^{-1} \mathrm{~m}^{-1}$ for treated water, which are low values. Along the treatment it is observed a decrease from the values of TSUVA and SUVA in raw surface water and also a decrease of SUVA in the NEU fraction, both having a sharp decrease after ozonation. The average value of TSUVA was $1.31 \mathrm{~L} \mathrm{mgC}^{-1} \mathrm{~m}^{-1}$ for treated water.

In spite of the evident efficiency of CoCoDAFF and ozonation and the low DOC in treated water, enhanced removal of the dominant NEU fraction would improve the treatment process.

\section{ACKNOWLEDGEMENTS}

The authors would like to thank the financial support by Águas do Douro e Paiva, S.A. This work has also been supported by Fundação para a Ciência e a Tecnologia (FCT) through grant no. PEstC/EQB/LA0006/2011. 


\section{REFERENCES}

Buchanan W., Roddick F., Porter N. and Drikas M. (2005). Fractionation of UV and VUV Pretreated Natural Organic Matter from Drinking Water, Environ. Sci. Technol., 39(12), 4647-4654.

Chow T.A., Suduan G. and Dahlgren R.A. (2005). Physical and chemical fractionation of dissolved organic matter and trihalomethane precursors: A review, J Water SRT - Aqua, 54(8), 33.

Chow C.W.K., Fabris R. and Drikas M. (2004). A rapid fractionation technique to characterise natural organic matter for the optimisation of water treatment processes, J Water SRT - Aqua, 53(2), 85-92.

Edzwald J. and Benschoten J. (1990). Aluminium coagulation of natural organic material. Chemical Water and Wastewater Treatment. Springer-Verlag, Berlin.

Gadmar T.C., Vogt R.D. and Evje L. (2005). Artefacts in XAD-8 NOM fractionation. Intern., J. Environ Anal. Chem., 85(6), 365 - 376.

Juhna T. and Melin E. (2006). Ozonation and biofiltration in water treatment - operational status and optimization issues, Techneau D.5.3.1 B.

Leenheer J.A. and Huffman E.W.D. (1976). Classification of organic solutes in water by using macroreticular resins, J. Res. U.S. Geol. Surv., 4(6), 737-751.

Nikolaou A.D., Kostopoulou M.N., and Lekkas T.D. (1999). Organic by-Products of drinking water chlorination, Global NEST: the Int. J., 1(3), 143-156.

Nikolaou A.D., Arhonditsis G., Kolovoyiannis V., Golfinopoulos S. and Lekkas T.D. (2003). Determination, interpretation and modeling of chlorination by-products concentrations in surface waters, Global NEST: the Int. J., 5(3), 157-164.

Rodriguez M.J., Serodes J. and Roy D. (2007). Formation and fate of haloacetic acids (HAAs) within the water treatment plant, Water Res., 41(18), 4222-4232.

Smith E.H. and Alqabany A.A. (2009). Fractionation of natural organic matter in the Nile River: Implications for treated water quality, Water Sci. Technol., 59(10), 1989-1997.

Swietlik J., Dabrowska A., Raczyk-Stanislawiak U. and Nawrocki J. (2004). Reactivity of natural organic matter fractions with chlorine dioxide and ozone, Water Res., 38(3), 547-558.

Weishaar J.L., Aiken G.R., Bergamaschi B.A., Fram M.S., Fujii R. and Mopper K., (2003). Evaluation of specific ultraviolet absorbance as an indicator of the chemical composition and reactivity of Dissolved organic carbon, Environ. Sci. Technol., 37(20), 4702-4708. 